\title{
Diagnóstico laboratorial do líquido amniótico
}

\author{
Laboratory diagnosis of amniotic fluid
}

\section{Sabrina Gonçalves Campana ${ }^{1}$ \\ Juliana Helena Chávez ${ }^{1}$ \\ Patrícia Haas ${ }^{2}$}

\begin{tabular}{|c|c|}
\hline unitermos & resumo \\
\hline $\begin{array}{l}\text { Líquido amniótico } \\
\text { Diagnóstico } \\
\text { Citologia }\end{array}$ & $\begin{array}{l}\text { O presente trabalho tem como objetivos a definição e a fisiologia do líquido amniótico, } \\
\text { ressaltando aspectos citológicos e principais técnicas para diagnóstico laboratorial das } \\
\text { patologias mais freqüentes. A metodologia utilizada foi a revisão bibliográfica atualizada } \\
\text { relacionando os aspectos citológicos com a idade gestacional e técnicas laboratoriais para } \\
\text { diagnóstico das principais patologias em que são observadas alterações do líquido amniótico, } \\
\text { concluindo-se que este é um importante componente do ambiente intra-uterino. Sua } \\
\text { produção e absorção dependem de uma série de mecanismos interdependentes entre o feto, } \\
\text { a placenta, as membranas e o organismo materno. Atualmente este fluido pode fornecer } \\
\text { inúmeras informações sobre a saúde fetal, realizando-se diversas técnicas, entre elas a } \\
\text { amniocentese e a dosagem de alfafetoproteína, que pode detectar defeitos do tubo neural e } \\
\text { trissomia do cromossomo } 21 \text {. A análise do líquido amniótico reforça a importância da } \\
\text { realização adequada de um pré-natal, sendo importante relacionar os resultados laboratoriais } \\
\text { com a clínica. }\end{array}$ \\
\hline
\end{tabular}

\section{abstract}

This present paper aims the definition of the amniotic fluid and its physiology standing out cytological aspects and main techniques for laboratorial diagnosis of the most frequent pathologies. The methodology was based on updated bibliographical research relating the cytological aspects with the pregnancy age and laboratorial techniques for diagnosis of the main pathologies in which alterations of the amniotic fluid are observed, concluding that this is an important component of the intrauterine environment. Its production and absorption depend on a series of interdependent mechanisms among the fetus, the placenta, the membranes and the maternal organism. Currently this fluid can supply innumerable information on the fetal health by the use of diverse techniques, among which, amniocentesis and dosage of alpha-fetoprotein, which can detect defects of the neural tube and trissomia of chromosome 21. The analysis of the amniotic fluid strengthens the importance of the adequate prenatal care, being important to relate the laboratorial results to clinical practice.

key words

Amniotic fluid

Diagnosis

Cytology

\section{Introducãa}

O líquido amniótico provém dos organismos materno e fetal, em proporções variáveis de acordo com a idade gestacional. Entre as suas principais funções destaca-se o crescimento externo simétrico do embrião, barreira contra infecções, impedindo também a aderência entre o embrião e o âmnio, protegendo o embrião de traumatismos sofridos pela mãe, ajudando a controlar a temperatura corporal do embrião e permitindo que o feto se mova livremente, contribuindo assim para o desenvolvimento muscular $(1,7)$.

Os principais componentes presentes neste líquido estão em suspensão e em dissolução. Entre os elementos em suspensão encontram-se células esfoliadas do âmnio, principalmente do feto, assim como lanu-
1. Acadêmica do curso de Farmácia-Bioquímica da Universidade Federal de Santa Catarina (UFSC). 2. Professora do Departamento de Análises Clínicas da UFSC. 
gem e gotículas de gordura. Como elementos de dissolução são encontradas substâncias orgânicas e inorgânicas. Os eletrólitos representam as substâncias inorgânicas, sendo alguns relacionados com a idade gestacional. Entre os compostos orgânicos estão as proteínas, os aminoácidos, a alfa-fetoproteína, as substâncias nitrogenadas não-protéicas, os lipídios, os carboidratos, as vitaminas, as enzimas, a bilirrubina, os hormônios e as prostaglandinas $(1,11)$.

A alfafetoproteína é uma glicoproteína sintetizada pelo saco vitelino fetal no início da gestação e posteriormente pelo trato gastrointestinal e pelo fígado. A sua principal fonte é a urina fetal. Os valores de referência estão relacionados com as metodologias e com os laboratórios. Embora sua função seja desconhecida, é a proteína sérica mais importante do embrião, podendo diagnosticar diversas patologias, sendo que alguns transtornos são associados com concentrações séricas maternas anormais de alfafetoproteína. Níveis elevados indicam defeitos do tubo neural (anencefalia, espinha bífida), cistos sacrococcígeos, obstrução esofágica ou intestinal, necrose hepática, defeitos da parede abdominal, obstrução urinária e outras anomalias renais, defeitos de osteogênese, defeitos congênitos de pele, baixo peso fetal, oligoidrâmnio, gestação múltipla. Já os níveis baixos indicam trissomias cromossômicas como síndrome de Down, doença trofoblástica gestacional, morte fetal e aumento do peso materno. O protocolo para análise de alfafetoproteína geralmente utilizado inclui: a) dosagem sérica materna de alfafetoproteína; b) repetir se o exame fornecer níveis alterados; c) ultra-sonografia; d) amniocentese para confirmação. A interpretação da dosagem da alfafetoproteína sérica materna é complexa, dependendo de fatores como idade, etnia, peso, idade gestacional e grau de nutrição $(3,5,12)$.

O líquido amniótico apresenta-se rico em células escamadas que delimitam a cavidade amniótica e também células provenientes do feto. A base morfológica da citologia amniótica está estritamente relacionada ao feto, decorrendo da necessidade de ser conhecido o desenvolvimento intra-uterino da pele, das mucosas respiratórias e digestivas, das coberturas geniturinárias e dos demais elementos que tenham contato com este líquido.Torna-se necessária ainda a investigação da fisiologia de cada epitélio, seus ritmos de crescimento e maturação (11).

Encontram-se na boca, no esôfago e no ânus do feto células do epitélio escamoso estratificado e sem cornificação. O restante do tubo digestivo, do estômago ao reto e nas glândulas anexas, apresenta composição de epitélios glandular, cúbico ou cilíndrico, secretores ou não. $\mathrm{Na}$ árvore respiratória encontra-se somente o epitélio respiratório (epitélios cilíndrico, pseudo-estratificado e ciliado). Nas vias urinárias há, fundamentalmente, epitélio transicional. Na genitália masculina, encontram-se epitélio glandular (próstata), canais deferentes e ejaculadores, epidídimo e túbulos testiculares, enquanto na genitália feminina é possível encontrar os epitélios vaginal, uterino e das trompas. Além destes elementos bem delimitados e corados, há presença de autólise de células com longo tempo de retenção, particularmente quando agrupadas, de mecônio, sangue, outros elementos celulares inflamatórios e microorganismos. Com isso, a citologia e a citopatologia amniótica podem diagnosticar: maturidade fetal, gestação de alto risco, morte fetal, infecções ovulares e sexo fetal (11).

No epitélio escamoso as células estão relacionadas com a espessura (função de diferenciação) e, em certos casos, com o período de maturação. As células visualizadas são: superficiais, cornificadas ou não (anucleadas ou em escamas e as picnóticas e pré-picnóticas), poligonais da camada espinhosa, geralmente do tipo intermediário e, por fim, células ovais ou redondas, imaturas e provenientes das camadas profundas (dos tipos basal e parabasal). No epitélio de transição as células encontradas geralmente se assemelham às células imaturas do epitélio escamoso, às vezes levemente poliédricas, com núcleos que vão de vesiculosos e de cromatina exuberante até a picnose. No epitélio glandular há presença de células cúbicas ou cilíndricas, secretoras ou não, que pouco descamam; por este motivo, com representação desprezível. Para orientação diagnóstica, basicamente, são utilizadas as células escamosas devido às suas quantidades e qualidades tintoriais, pelo aspecto dos núcleos e características do citoplasma. As preparações normalmente são feitas por citocentrifugação, visando à melhor padronização e à permissão de comparações. As colorações policrômicas utilizadas são: Shorr e Papanicolaou, sendo utilizado à parte o sulfato azul de Nilo a 0,1\%, com a vantagem de separar quanto ao grau de maturidade (11).

Benavides et al., em estudo para determinar o valor citológico do líquido amniótico no diagnóstico pré-natal do sexo, demonstrou uma significativa diferença na citologia de fetos masculinos e femininos, já que nestes últimos encontrou um maior número de células, com predomínio de células intermediárias basófilas e células naviculares, em comparação com a menor quantidade de células e predomínio de células escamosas intermediárias e superficiais acidófilas com ausência de células naviculares nos fetos masculinos (2). 
Escobosa et al. determinaram o grupo sangüíneo fetal no líquido amniótico em gestações de 37 a 40 semanas. A determinação do grupo sangüíneo nas células amnióticas foi realizada por imunofluorescência. Ao nascimento, foram obtidas amostras de sangue do cordão umbilical e nelas determinou-se o grupo sangüíneo dos eritrócitos fetais. Os casos de grupos sangüíneos determinados nas células amnióticas coincidiram com o encontrado no sangue dos produtos fetais ao nascimento (6).

Duas técnicas são utilizadas no estudo do líquido amniótico durante a gravidez: amniocentese e amnioscopia. Amniocentese consiste na introdução de uma aguIha longa através da parede abdominal da mãe para a retirada do líquido amniótico, sendo que o volume do líquido retirado depende da idade do feto e do motivo do exame. Amnioscopia é um método endoscópico de observação da câmara amniótica, permitindo observá-la pelo canal cervical e através das membranas do pólo inferior do ovo $(11,13)$.

A amniocentese e a subseqüente análise do líquido amniótico são utilizadas para detectar principalmente: doenças congênitas, defeitos de tubo neural, idade gestacional e maturidade fetal pulmonar, sendo indicada principalmente a mulheres acima de 35 anos devido à maior probabilidade de anormalidades cromossômicas fetais (síndrome de Patau e Edwards), além de tornar possível o estudo do DNA (paternidade). A amniocentese é um procedimento seguro, com risco de perda fetal geralmente menor do que $1 \%$, uma vez que o método pode ser oferecido às mulheres selecionadas após serem revistos os riscos e os benefícios envolvidos. É importante ressaltar que muitos defeitos do nascimento não podem ser detectados pela amniocentese $(3,8,13)$.

O diagnóstico de anormalidades genéticas no líquido amniótico é realizado através de cultura de células. A amostra é obtida entre 14 e 20 semanas de gestação, uma vez que as células coletadas são cultivadas e lisadas para análise cromossômica, determinando-se seu conteúdo enzimático para avaliar defeitos de metabolismo. A doença hemolítica do recém-nascido, síndrome resultante de incompatibilidade Rh entre o sangue materno e o fetal, pode ser diagnosticada no líquido amniótico. Esta patologia é desencadeada por anticorpos maternos contra os eritrócitos fetais, causando uma reação hemolítica que pode variar em severidade. Os produtos resultantes da quebra de hemoglobina, predominantemente bilirrubina, aparecem no líquido amniótico e fornecem uma medida da severidade da incompatibilidade da reação. $\mathrm{O}$ método mais usado para dosagem destes produtos é a espectrofotometria direta do líquido amniótico não-diluído e subseqüente cálculo da quantidade de bilirrubina. Cuidados devem ser tomados na interpretação do espectro. A decisão do tratamento pode ser baseada no grau de hemólise e na idade gestacional. Nesta técnica encontram-se como interferentes a urina materna, o sangue fetal ou maternal e o mecônio (material fecal do feto) (3).

Para o acompanhamento da gravidez é importante a determinação da idade gestacional. Quatro parâmetros têm sido usados para esta determinação: creatinina, que reflete a massa muscular fetal; uréia, que está relacionada com as proteínas; ácido úrico, que está relacionado com os nucleotídeos; e osmolalidade, que está relacionada com todos os anteriores. O problema básico do uso destes parâmetros é a alta taxa de variação na concentração e a falta de especificidade, impossibilitando um diagnóstico preciso. A ultra-sonografia tornou-se a melhor ferramenta para estimar a idade gestacional e o tamanho e o sexo fetais (3).

Quando a amniocentese for executada para avaliar a maturidade fetal pulmonar, realiza-se uma técnica, freqüentemente entre 32 e 36 semanas de gestação, observando-se o tipo de células epiteliais alveolares fetais predominante, além de correlacionar a concentração de fosfolipídeos, particularmente compostos como fosfatidilglicerol e lecitina, com o avanço do desenvolvimento pulmonar fetal. Em mulheres diabéticas, o teste da maturidade pulmonar pode ser feito no final da gestação, porque esta patologia pode retardar a maturidade pulmonar fetal $(3,13)$.

Com o desenvolvimento das técnicas moleculares, o líquido amniótico pode fornecer inúmeras informações, quando analisado pela técnica de PCR, detectando infecções materno-fetais como rubéola, citomegalovírus e toxoplasmose (8).

O líquido amniótico pode ser uma importante fonte de células para a engenharia tecidual fetal, onde podem ser formados tecidos, utilizados para defeitos congênitos que a cirurgia não pode reparar. Cientistas afirmam que uma amostra de $2 \mathrm{ml}$ de fluido amniótico pode fornecer células suficientes para esta finalidade, sendo este procedimento menos invasivo do que coletar células do próprio feto (9).

É importante considerar o volume do líquido amniótico, sendo que este se relaciona com algumas patologias como poliidrâmnio e oligoidrâmnio. O poliidrâmnio é o acúmulo patológico de líquido amniótico, associado 
a uma elevada morbimortalidade materna e perinatal Considera-se poliidrâmnio quando o volume amniótico ultrapassa os $2.000 \mathrm{ml}$, sendo que as causas principais que levam a este aumento são malformação fetal, distúrbios genéticos, diabetes melito, sensibilização Rh e infecções congênitas (10).

O oligoidrâmnio é definido como uma diminuição na quantidade de líquido amniótico (menos de $400 \mathrm{ml}$ ), constituindo uma grave complicação da gravidez. As anomalias fetais resultantes desta condição são na maioria das vezes malformações do sistema urinário. Alguns estudos demonstram que fetos de gestantes hipertensas com associação de oligoidrâmnio são potencialmente suscetíveis a hipóxia, principalmente durante o período intraparto, e tendem a apresentar sinais de asfixia após o nascimento $(4,10,14)$.

Técnicas de diluição para determinação de oligoidrâmnio foram empregadas anteriormente. Substâncias químicas como albumina sérica radioativa, vermelho Congo, azul de Evans, amino-hipurato de sódio e azul de cromassie eram utilizadas acarretando risco muito elevado à gestante, sendo substituídas na atualidade por diagnóstico ultra-sonográfico (4).

Com base nos aspectos expostos anteriormente conclui-se que o líquido amniótico é um importante componente do ambiente intra-uterino. Sua produção e sua absorção dependem de uma série de mecanismos interdependentes entre o feto, a placenta, as membranas e o organismo materno. Atualmente este fluido pode fornecer inúmeras informações sobre a saúde fetal utilizando como ferramentas as diversas técnicas já descritas. A análise do líquido amniótico reforça a importância da realização adequada de um pré-natal, sendo importante ressaltar que todos os resultados laboratoriais devem ser relacionados com a clínica.

\section{Referências}

1. Belfort, P. \& O rland, O. M edicina perinatal. São Paulo: Manole, 1993. p. 39-45.

2. Benavides, I. et al. Utilidad de la citolo gía del líquido amniótico en el diagnóstico prenatal del sexo. Ginecol. Obstet. M ex., 51(312): 83-7, 1983.

3. Bishop, M.L. et al. Clinical Chemistry. Lippincott-Raven Publishers, 1996. p. 469-73.

4. Cha, S. \& Zugaib, M. M edicina Fetal. São Paulo:Atheneu, 1993. p. 231-42.

5. Cunningham, M. et al. W illiams Obstetricia. 20. ed. Buenos A ires: Médica Panamericana, 20. ed., 1998. p. 859-66.

6. Escobosa,V. et al. D eterminación del grupo sanguíneo fetal en células amnióticas. Arch. Invest. M ed., 13(2): 101-4, 1982.

7.Geocities. D isponível em:<http://www.geocities.com/medpucpr/ fisiol_liq_amn.htm>.
8. Maringá Saúde. Disponível em: <http://maringasaude.com.br/ fetalmed/medfetal.shtml>.

9. Mitka, M.A mniotic cells show promise for fetal tissue engineering. JAMA, 286(17): 2083, 2001.

10. Reece, E.A. et al. Compêndio de Medicina Fetal e Materna. Porto A legre:Artes Médicas, 1996. p. 242-8.

11. Rezende,J. et al. O bstetrícia. Rio de Janeiro: G uanabara Koo gan, 8. ed., 1998. p. 204-9.

12. SBCM. Disponível em: <http://www.sbcm-rj.org/sbcm-rj/ academico/dicas/>.

13. Site Médico. D isponível em: <http://www.sitemedico.com.br/ seja_informado/doenc $>$.

14. So gesp. Disponível em: <http://www.sogesp.com.br/jornal/ 26a_ed/tese01.html>. 